\title{
Pengukuran Kinerja Rantai Pasok pada PT. Louserindo Megah Permai Menggunakan Model SCOR dan FAHP
}

\author{
Sarah Azmiyati ${ }^{1}$, Syarif Hidayat ${ }^{2}$ \\ ${ }^{1,2}$ Program Studi Teknik Industri, Fakultas Sains dan Teknologi, Universitas Al-Azhar Indonesia, \\ Jalan Sisingamangaraja, Kompleks Masjid agung Al Azhar, Kebayoran Baru, Jakarta Selatan 12110
}

Penulis untuk Korespondensi / E-mail: sarahazmiyati25@gmail.com

\begin{abstract}
Abstrak - Tantangan yang dihadapi dunia manufaktur, seiring dengan berkembangnya zaman selalu berubah dan semakin berat dari masa ke masa. Keunggulan bersaing pada era ini tidak hanya ditentukan oleh kemampuan suatu industri dalam menciptakan banyak output persatuan waktu. Produktifitas memang penting, tetapi tidak cukup sebagai bekal untuk bersaing dipasar. Pelanggan mulai bisa membedakan produk berdasarkan kualitasnya. Kualitas produk pun sangat bergantung pada proses, manusia, dan sistem secara keseluruhan. Pengendalian kualitas tidak lagi cukup hanya dilakukan dengan model inspeksi produk, tetapi lebih fundamental dengan melihat proses. PT. Louserindo Megah Permai (LMP) merupakan perusahaan yang menerapkan manajemen rantai pasok pada setiap proses produksinya. Pada penelitian ini akan dilakukan pengukuran kinerja terhadap manajemen rantai pasok pada proses elemen stage finished product dan release finished product to deliver pada LMP. Metode yang dipakai dalam mengukur kinerja tersebut adalah metode SCOR yang dibantu dengan metode FAHP (Fuzzy Analytical Hierarchy Process) dalam proses menentukan bobot pada setiap metrics. Dari hasil perhitungan tersebut maka akan diketahui indikator kinerja perusahaan yang tergolong rendah sehingga bisa diberikan usulan perbaikan serta diketahui metrics apa saja yang sangat mempengaruhi kinerja pekerja pada LMP. Penelitian ini dilakukan berdasarkan pada penurunan selama 4 tahun terakhir (2010-2014) di LMP pada tingkat penjualan lift dan hanya mengalami kenaikan sebesar rata-rata hanya 10\%. Oleh karena itu perusahaan perlu melakukan pengukuran kinerja supply chain untuk mengetahui sejauh mana performansi supply chain perusahaan telah tercapai. 2. Dari hasil pengukuran kinerja rantai pasok LMP untuk periode tahun 2015, didapatkan nilai kinerja sebesar $73.82 \%$, yang termasuk dalam kategori Good menurut Hvolby (2000). Dari perhitungan pada indikator kinerja SCOR yang telah dilakukan, didapatkan 9 metrics yang nilai kinerjanya rendah, yaitu: Delivery Performance to Customer Commit Date [60\%], \%Faultless Installation [55\%], Days Payable Outstanding [25\%], Rout Shipments Cycle Time [60\%], Deliver Cycle Time [30\%], Ship Product Cycle Time [60\%], Load Vehicle \& Generate Shipping Documentation Cycle Time [60\%] dan Install Product Cycle Time [30\%].
\end{abstract}

Kata Kunci - Pengukuran kinerja, Manajemen Rantai Pasok, SCOR, Fuzzy Analytical Hierarchy Process

Abstract - The challenges faced the manufacturing world, along with the evolution of the ever changing and increasingly heavy from time to time. Competitive advantage in this era not only determined by the ability of industry in creating a lot of unity output time. Productivity is important but enough as a provision to complete in the market. Customer can be begin to differentiate products based on their quality. Product quality is highly dependent on process, human, and system as a whole. Quality control is not only done with the product inspection model, but more fundamentally by looking at the process. PT. Louserindo Megah Permai is company that implemented supply chain management in each production process. In this research, performance measurement of supply chain management on stage finish product element process and finished product to deliver on LMP. The method used in measuring the performance is SCOR method wich is assisted by FAHP (Fuzzy Analytical Hierarchy Process) method in the process determining the weight of each metrics. From the results of these calculations it will be known 
indicators of company performance are low so that it can be given suggestions for improvement and known metrics what are affecting the performance of workers in LMP. This study is based on decline over the last 4 year (2010-2014) in LMP at the level of elevator sales and only increased by on average of only $10 \%$. Therefore, companies need to measure supply chain performance to know the extent to which the company's supply chain performance has been achieved. 2 . From the results of LMP supply chain performance measurement for the period of 2015, obtained a performance value of $\mathbf{7 3 . 8 2 \%}$, which is included in the category of Good according to Hvolby (2000). From the calculation on SCOR performance indicator that has been done, got 9 metrics that its performance value is low, that is: Delivery Performance to Customer Commit Date [60\%],\% Faultless Installation [55\%], Days Payable Outstanding [25\%], Rout Shipments Cycle Time [60\%], Deliver Cycle Time [30\%], Ship Product Cycle Time [60\%], Load Vehicle \& Generate Shipping Documentation Cycle Time [60\%] and Install Product Cycle Time [30\%].

Keywords - Performance Measurements, Supply Chain Management, SCOR, Fuzzy Analytical Hierarchy

Process

\section{PENDAHULUAN}

$\mathrm{T}$ antangan yang dihadapi dunia manufaktur, seiring dengan berkembangnya zaman selalu berubah dan semakin berat dari masa ke masa. Keunggulan bersaing pada era ini tidak hanya ditentukan oleh kemampuan suatu industri dalam menciptakan banyak output persatuan waktu. Produktifitas memang penting, tetapi tidak cukup sebagai bekal untuk bersaing dipasar. Pelanggan mulai bisa membedakan produk berdasarkan kualitasnya. Kualitas produk pun sangat bergantung pada proses, manusia, dan sistem secara keseluruhan. Pengendalian kualitas tidak lagi cukup hanya dilakukan dengan model inspeksi produk, tetapi lebih fundamental dengan melihat proses (Pujawan, 2010).

PT. Louserindo Megah Permai (LMP) merupakan perusahaan yang bergerak di bidang manufaktur pembuatan elevator. Perusahaan ini telah memproduksi lebih dari 2000 elevator dan memiliki lebih dari 50 supplier untuk memasok kebutuhan komponen materialnya. Jenis elevator yang diproduksi diantaranya adalah passenger lift, bed lift, home lift, dumbwaiter, escalator, dan travolator. Untuk menjaga kepercayaan pelanggan, LMP sudah bersertifikat ISO 9001: 2008 (LMP, 2002). LMP merupakan perusahaan yang menerapkan manajemen rantai pasok pada setiap proses produksinya. Pada penelitian ini akan dilakukan pengukuran kinerja terhadap manajemen rantai pasok pada proses elemen stage finished product dan release finished product to deliver pada LMP. Metode yag dipakai dalam mengukur kinerja tersebut adalah metode SCOR yang dibantu dengan metode FAHP (Fuzzy Analytical Hierarchy Process) dalam proses menentukan bobot pada setiap metrics. Dari hasil perhitungan tersebut maka akan diketahui indikator kinerja perusahaan yang tergolong rendah sehingga bisa diberikan usulan perbaikan serta diketahui metrics apa saja yang sangat mempengaruhi kinerja pekerja pada LMP.

\section{TINJAUAN PUSTAKA}

\section{Supply Chain}

Supply chain adalah jaringan perusahaanperusahaan yang secara bersama-sama bekerja untuk menciptakan dan menghantarkan suatu barang ke tangan pemakai akhir, bisa dikatakan supply chain merupakan jaringan fisik perusahaan-perusahaan yang terlibat dalam memasok barang, memproduksi barang, maupun mengirimkannya ke pemakai akhir (Pujawan, 2010). Untuk meningkatkan dan mencapai supply chain yang efektif, perusahaan harus mengambil keputusan secara kolektif sehubungan dengan 5 (lima) proses pendorong utama supply chain, yaitu proses produksi, manajemen inventori, pemilihan transportasi, lokasi, dan aliran informasi (Hugo, 2003).

\section{Supply Chain Management}

Supply Chain Management (SCM) sebenarnya istilah ini banyak digunakan dan dan berkembang sejak tahun 1980an. Tetapi banyak orang yang mengartikan SCM sebagai pengganti dari istilah logistik. Namun arti yang sebenarnya lebih luas. SCM adalah integrasi beberapa kunci proses bisnis dari end user 
hingga para pemasok yang menyediakan produk, jasa, dan informasi yang menjadi nilai tambah untuk para pelanggan dan stakeholder (Douglas M. Lambert et al, 2004).

Suatu rantai pasok mencakup semua tahap, yang secara langsung atau tak langsung, dalam memenuhi permintaan pelanggan. Rantai pasok itu tidak hanya mencakup perusahaan manufaktur dan pemasok, tetapi juga pihakpihak yang terlibat dalam kegiatan transportasi, pergudangan, pengecer, dan para pelanggan itu sendiri. Dalam setiap organisasi, rantai pasok tersebut mencakup semua fungsi yang terlibat dalam pemenuhan permintaan pelanggan (Chopra dan Meindl, 2001).

\section{Supply Chain Operation Reference}

SCOR (Supply Chain Operation Reference) merupakan suatu model konseptual yang dikembangkan oleh Supply Chain Council (SCC), sebuah organisasi non-profit independent, sebagai standar antar industri (cross industry). Tujuan dari standarisasi yang dilakukan SCC adalah untuk memudahkan pemahaman rantai pasok sebagai suatu langkah awal dalam rangka memperoleh suatu manajemen rantai pasok yang efektif dan efisien dalam menopang strategi perusahaan. Organisasi yang terbentuk pada tahun 1996 oleh Pittligio, Rabin, Todd dan McGrath (PRTM) dan lembaga riset AMR di Amerika ini, beranggotakan 69 orang sukarelawan yang terdiri dari para praktisi dunia industri dan para peneliti. SCOR Model mempunyai kerangka yang menggabungkan antara proses bisnis rantai pasok, pengukuran kinerja berdasarkan best practice ke dalam suatu struktur yang terintegrasi sehingga proses komunikasi antar pelaku rantai pasok dan aktivitas manajemen rantai pasok dapat berjalan secara optimal (www.supplychain.org, 2006).Gambar 1 Proses Inti Supply Chain Pada

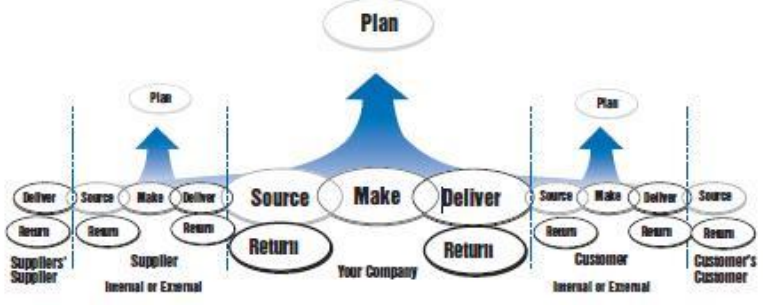

Gambar 1. Model SCOR (Sumber: Supply Chain Council)
Merupakan proses-proses yang menyeimbangkan permintaan dan pasokan secara menyeluruh yang bertujuan untuk mengembangkan kebutuhan pengiriman, produksi dan pasokan secara optimal. Plan mencakup proses menaksir kebutuhan distribusi, perencanaan dan pengendalian persediaan, perencanaan produksi, perencanaan material, perencanaan kapasitas dan melakukan penyesuaian supply chain plan dengan financial plan.

\section{Source}

Merupakan Proses-proses pembelian barang dan jasa yang bertujuan untuk memenuhi permintaan aktual atau yang direncanakan. Jadi proses bisa bergantung pada apakah barang yang dibeli termasuk stocked, make to order, atau engineer-to-order products.

\section{Make}

Merupakan proses transformasi material menjadi produk akhir untuk memenuhi permintaan aktual yang direncanakan. Kegiatan make atau produksi dapat dilakukan atas dasar ramalan untuk memenuhi target stok (make-tostock), atas dasar pesanan (make-to-order), atau engineer-to-order. Proses yang terlibat disini adalah pejadwalan produksi, melakukan kegiatan produksi dan melakukan pengetesan kualitas, mengelola barang setengah jadi, memelihara fasilitas produksi, dll.

\section{Deliver}

Merupakan proses-proses penyediaan produk jadi/jasa untuk memenuhi permintaan aktual ataupun yang direncanakan, mencakup manajemen pemesanan, manajemen transportasi, dan juga distribusi. Proses yang terlibat diantaranya adalah menangani pesanan dari pelanggan, memilih perusahaan jasa pengiriman, menangani kegiatan pergudangan produk jadi dan mengirim tagihan ke pelanggan.

\section{Return}

Merupakan proses-proses yang diasosiakan dengan pengembalian dan penerimaan produk dengan kategori pengembalian produk. Proses ini diperluas hingga kelayanan setelah pengiriman produk kepada konsumen. Postdelivery-customer support juga merupakan bagian dari return (Sumber: Supply chain Council).

\section{Plan}


Fuzzy Analytical Hierarchy Process (FAHP) Metode FAHP digunakan untuk pemilihan suatu alternative dan penyesuaian masalah dengan menggabungkan konsep teori fuzzy dan analisis struktur hierarki. Penggunaan metode fuzzy memungkinkan pengambilan keputusan untuk memasukkan data kualitatif dan kuantitatif ke dalam model keputusan. Dengan alasan ini, pengambil keputusan biasanya lebih merasa yakin untuk memberi penilaian dalam bentuk rentang daripada penilaian dalam bentuk nilai tertentu.

Teori fuzzy adalah suatu teori matematika yang dirancang dengan model ketidaktepatan atau ke-ambiguity-an dari proses kognitif manusia yang dipelopori oleh Zadeh (Marimin 2013). Kunci gagasan teori fuzzy adalah suatu unsur mempunyai suatu tingkat derajat keanggotaan (membership degree) dalam suatu keadaan yang tidak jelas (negoita 1985; Zimmermann 1996). Fungsi keanggotan menunjukkan nilai keanggotaan suatu unsur dalam suatu himpunan. Nilai keanggotaan suatu unsur berkisar 0 dan 1 . Unsur dapat mempunyai satu himpunan derajat keanggotaan tertentu dan dapat juga mempunyai berbagai himpunan. Teori fuzzy memperbolehkan keanggotaan unsur secara parsial. Transisi antara keanggotaan tertentu dan non keanggotaan secara bertahap. Fungsi keanggotaan memetakan variasi nilai variabel dari nilai linguistik ke dalam kelas linguistik yang berbeda. Adaptasi dari fungsi keanggotaan untuk variabel linguistik ditentukan melalui pengetahuan ahli yang sebelumnya mengetahui tentang variabel linguistik, menggunakan format sederhana secara geometris (triangular, trapezoidal, atau fungsi-s), serta proses trial and error.

Di anatara fungsi keanggotaan yang umum dipakai, triangular dan trapezoidal merupakan fungsi yang pealing sering dipakai karena kemudahan dalam pemodelan dan interpretasinya yang mudah (Bazzazi et al. 2008).

\section{METODE PENELITIAN}

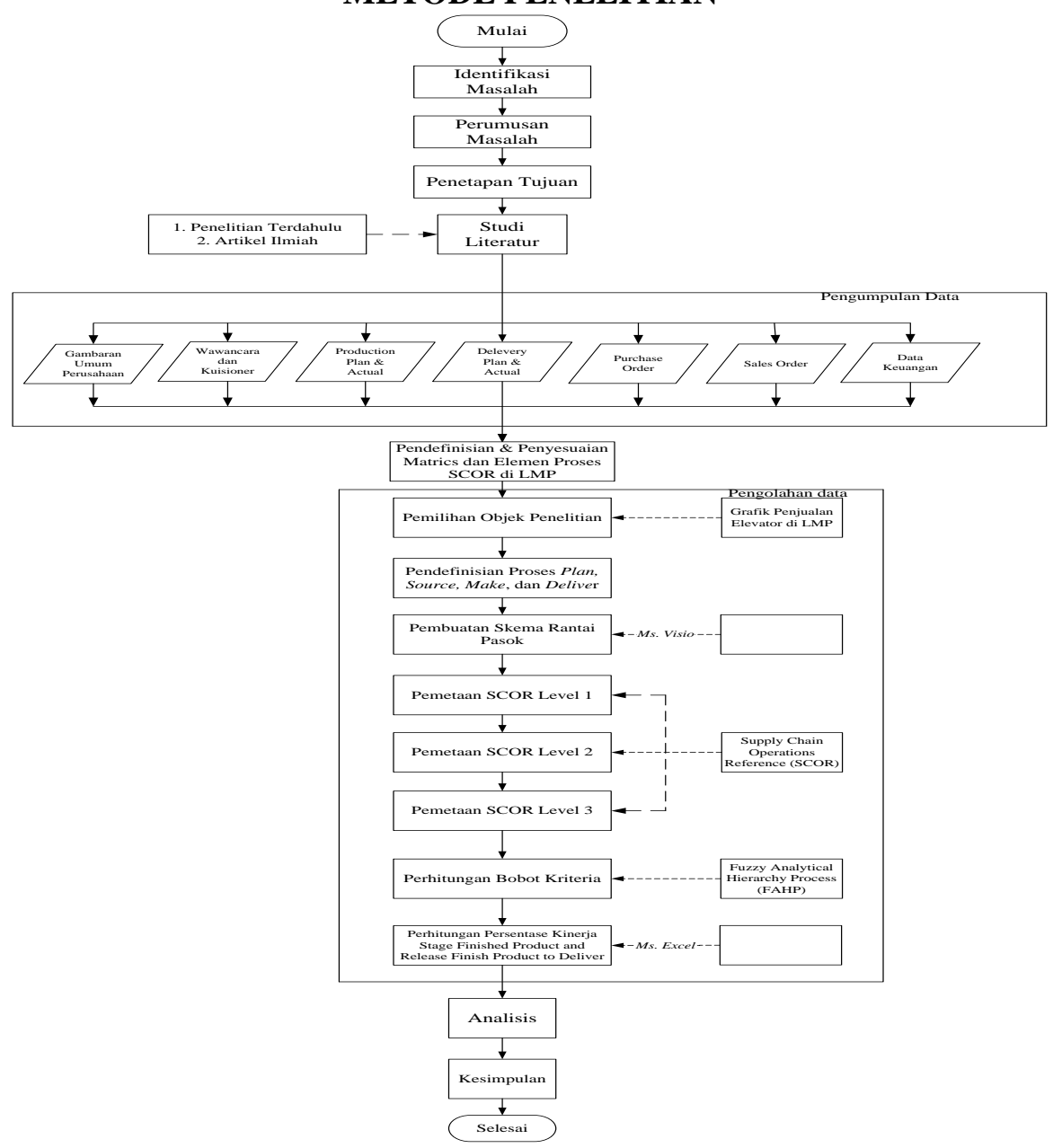

Gambar 2. Flowchart Penelitian 


\section{HASIL DAN PEMBAHASAN}

\section{Pengumpulan Data}

Data-data yang dikumpulkan untuk melakukan pengukuran kinerja rantai pasok pada LMP antara lain: gambaran umum perusahaan, production plan and actual, delivery plan and actual, purchase order, sales order, data keuangan, dan data aset. LMP memproduksi beberapa jenis tipe lift yaitu passenger, bedlift, homelift, dumbwaiter, eskalator dan travolator. Dari beberapa jenis tipe lift tersebut akan dipilih salah satu jenis tipe lift berdasarkan data pesanan yang paling banyak. Gambar 3 merupakan tabel pesanan lift pada LMP.

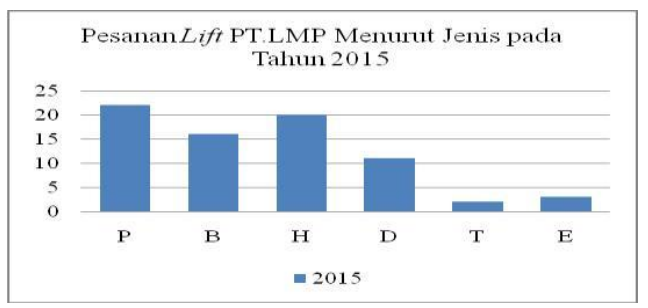

Gambar 3. Data Pesanan Lift

\section{Pengolahan Data}

Data-data yang dibutuhkan telah terkumpul, selanjutnya adalah tahap pengolahn data yang dilakukan berdasarkan tahap proses rantai pasok pada LMP. Gambar 4 merupakan gambar proses inti rantai pasok pada LMP

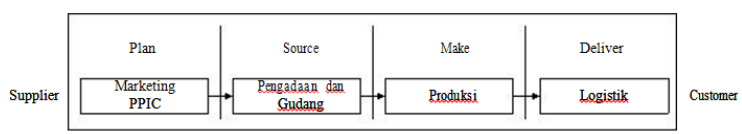

Gambar 4. Proses Inti Rantai Pasok LMP

(Sumber: Louserindo Megah Permai)

Selanjutnya adalah mengidentifikasi proses-proses bisnis yang dilakukan LMP pada setiap proses inti rantai pasok. Gambar 5 merupakan skema rantai pasok pada LMP.

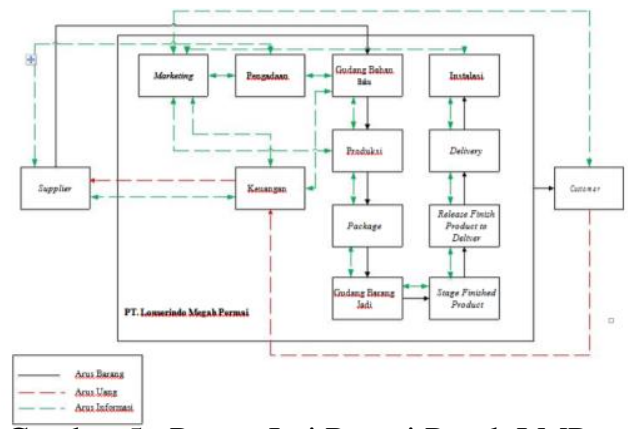

Gambar 5. Proses Inti Rantai Pasok LMP
Pada skema rantai pasok yang telah dibuat berdasarkan proses bisnis di LMP, maka selanjutnya adalah menyusun metrikmetrik pada SCOR yang disusun distruktur hirarki pada Gambar 6.

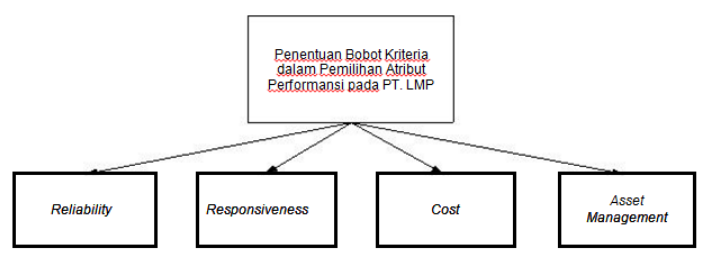

Gambar 6 Proses Inti Rantai Pasok LMP

FAHP merupakan tahap pengpalahan data untuk mendapatkan bobot pada setiap metrik yang tertera pada struktur hirarki. Gambar 7 merupakan gugusan fuzzy triangular pada perhitungan FAHP.

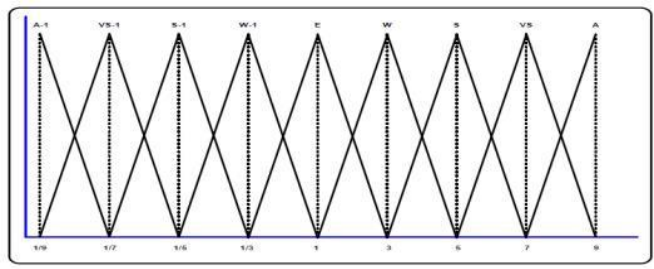

Gambar 7 Proses Inti Rantai Pasok LMP

Berdasarkan gugus fuzzy triangular yang telah dibuat, maka akan dibuat data linguistik yang tertera pada Tabel 1 .

Tabel 1. Data Linguistik

\begin{tabular}{ccccc}
\hline & & $\mathrm{a}$ & $\mathrm{b}$ & $\mathrm{C}$ \\
\hline Absolutely & (A-1) & 0,1111 & 0,1111 & 0,1429 \\
Very Strong & (V-1) & 0,1111 & 0,1429 & 0,2000 \\
Strong & $(\mathrm{S}-1)$ & 0,1429 & 0,2000 & 0,3333 \\
Weak & (W-1) & 0,2000 & 0,3333 & 1,0000 \\
Equal & $\mathrm{E}$ & 0,3333 & 1,0000 & 3,0000 \\
Weak & (W) & 1,0000 & 3,0000 & 5,0000 \\
Strong & (S) & 3,0000 & 5,0000 & 7,0000 \\
Very Strong & (V) & 5,0000 & 7,0000 & 9,0000 \\
Absolutely & (A) & 7,0000 & 9,0000 & 9,0000 \\
\hline
\end{tabular}

Setelah dilakukan perhitungan, maka akan dilihat konsistensi dari jawaban setiap pakar. Tabel 2 merupakan tabel nilai konsistensi pada setiap pakar.

Tabel 2. Konsistensi Pakar

\begin{tabular}{lccc}
\hline & Pakar 1 & Pakar 2 & Pakar 3 \\
\hline Nilai CR & 0,08 & 0,09 & 0,10 \\
\hline
\end{tabular}


Jika jawaban dari setiap pakar sudah konsisten, maka hal yang dilakukan selanjutnya adalah menentukan bobot dari setiap kriteria metrik yang telah dirangkum pada Tabel 3.

Tabel 3. Bobot Kriteria SCOR

\begin{tabular}{lcc}
\hline KRITERIA & BOBOT & RANKING \\
\hline Reliability & 0,1176 & 4 \\
\hline Responsiveness & 0,1793 & 3 \\
\hline Cost & 0,2328 & 2 \\
\hline Asset Management & 0,4702 & 1 \\
\hline
\end{tabular}

Tahapan pengolahan data selanjutnya adalah menghitung nilai SCOR pada setiap proses bisnis pada LMP yang sesuai dengan skema rantai pasok yang telah dibuat. Tabel 4 merupakan contoh perhitungan untuk salah satu proses bisnis pada LMP yaitu proses pengiriman barang ke pelanggan. Tabel 4 merupakan tabel keakuratan pengiriman setiap kuantitas pada tipe passenger lift.

Tabel 4 Akurasi Pengiriman Kuantitas Barang

\begin{tabular}{|c|c|c|c|c|}
\hline No & $\begin{array}{l}\text { Kode } \\
\text { Proyek }\end{array}$ & $\begin{array}{l}\text { Unit } \\
\text { Order }\end{array}$ & $\begin{array}{l}\text { Unit } \\
\text { Sent }\end{array}$ & $\begin{array}{l}\text { Gap } \\
\text { (unit) }\end{array}$ \\
\hline 1 & L0348 & 1 & 1 & 0 \\
\hline 2 & L0349 & 1 & 1 & 0 \\
\hline 3 & L0350 & 1 & 1 & 0 \\
\hline 4 & L0351 & 1 & 1 & 0 \\
\hline 5 & $\mathbf{L 0 3 5 2}$ & 1 & 1 & 0 \\
\hline 6 & $\mathbf{L 0 3 5 3}$ & 1 & 1 & 0 \\
\hline 7 & $\overline{L B 154}$ & 1 & 1 & 0 \\
\hline 8 & L0362 & 1 & 1 & 0 \\
\hline 9 & L0365 & 1 & 1 & 0 \\
\hline 10 & L0367 & 1 & 1 & 0 \\
\hline 11 & L0368 & 1 & 1 & 0 \\
\hline 12 & L0370 & 1 & 1 & 0 \\
\hline 13 & L0373 & 1 & $\overline{1}$ & $\overline{0}$ \\
\hline 14 & L0374 & 1 & 1 & 0 \\
\hline 15 & L0375 & 1 & 1 & 0 \\
\hline 16 & L0376 & 2 & 0 & 2 \\
\hline 17 & L0378 & 2 & 2 & 0 \\
\hline 18 & L0380 & 1 & 1 & 0 \\
\hline 19 & L0382 & 1 & 1 & 0 \\
\hline 20 & L0383 & 1 & 1 & 0 \\
\hline \multicolumn{2}{|c|}{ Total } & 22 & 20 & 2 \\
\hline \multirow{2}{*}{\multicolumn{4}{|c|}{ RL.2.1\% of orders delivered in full }} & \multirow{2}{*}{$90,91 \%$} \\
\hline \multicolumn{2}{|c|}{ RL.3.35\% delivery aty accuracy } & & & \\
\hline
\end{tabular}

Hasil perhitungan yang dilakukan berdasar pada ketentuan rumus perhitungan yang telah ditentukan oleh supply chain council.
Delivery Quantity Accuracy =

Total number of orders delivered match the order quantities $\mathrm{X}$

$100 \%$

Untuk semua perhitungan SCOR pada setiap proses bisnis sama yaitu dengan berdasar pada aturan supply chain council. Tabel 5 merupakan rekapitulasi perhitungan SCOR pada setiap proses bisnis di LMP.

\section{KESIMPULAN}

Kesimpulan yang didapatkan dari proses SCOR di LMP terdiri dari 4 proses inti yaitu

Plan, Source, Make, dan Deliver. Plan dilakukan oleh Marketing dan PPIC; Source oleh Pengadaan dan Gudang; Make oleh Produksi, dan Deliver oleh Logistik.

Variabel pengukuran yang digunakan adalah customer-focused meliputi metrics Reliability [Perfect Order Fulfillment], Cost [Total Supply Chain Management Cost], Asset Management [Cash to Cash Cycle Time] dan Responsiveness [Order Fulfillment Cycle Time]. Untuk tahun 2015, nilai kinerja LMP adalah $81,02 \%$, dan masuk kategori Good menurut sistem monitoring indikator performansi oleh Hvollby. Didapatkan 9 metrics yang nilai kinerjanya rendah, yaitu:

1) Delivery Performance to Customer Commit Date [60\%]

2) \%Faultless Installation [55\%]

3) Rout Shipments Cycle Time [60\%]

4) Deliver Cycle Time [30\%]

5) Ship Product Cycle Time [60\%]

6) Load Vehicle \& Generate Shipping Documentation Cycle Time [60\%]

7) Install Product Cycle Time [30\%].

Jumlah waktu antara perusahaan membayar material ke supplier dan menerima pembayaran dari pelanggan untuk produk yang dibuat dari material yaitu 325 hari untuk 1 periode yaitu Januari 2015 - November 2015.

\section{DAFTAR PUSTAKA}

[1] Bolstorff, Peter and Rosenbaum, Robert. 2007.

[2] Supply Chain Excellence: A Handbook for Dramatic Improvement Using The SCOR Model. New York: Amacom. 
[3] Chopra, S., and Meindl, P. 2007. Supply Chain Management: Strategy, Planning, and Operations. New Jersey: New Jersey - Prentice-Hall

[4] Dilworth, James B. (2000). "Operating Management: Providing Value in Goods and Services". 3rd Edition. Orlando: The Dryen Press Harcourt College Publisher.

[5] Hugo, Michael. 2003. Essential of Supply Chain Management. New Jersey: John Willey \& Sons Inc.

[6] Hvolby, 2000. Performance

Measurement and Improvement Supply Chain. Thienekers

[7] Indrajit, Richardus Eko dan Djokopranoto. 2003. Konsep Manajemen Supply Chain: Strategi Mengelola Manajemen Rantai Pasokan Bagi Perusahaan Modern di Indonesia. Jakarta : PT Gramedia Widiasarana Indonesia.

[8] Kusumadewi, Sri. 2006. Fuzzy MultiAttribute Decision Making. Graha Ilmu. Yogyakarta.

[9] Marimin. 2013. Teknik dan Analisis Pengambilan Keputusan dalam Manajemen Rantai Pasok. IPB Press. Bogor.

[10] Maryam, Sinta. 2016. Analisis Penentuan Bobot Kriteria dalam Pemilihan Supplier Proses Procurement PT.M3 Ketapang Sejahtera dengan Metode Fuzzy AHP. Jakarta: Universitas Al Azhar Indonesia.

[11] Mustakin, Anas. 2011. Pengukuran Kinerja Manajemen Rantai Pasokan dengan SCOR Model 9.0. Bogor: Institut Pertanian Bogor.

[12] Nurhasanah, Nunung. Analisis Pemilihan Supplier Untuk Pemesanan Bahan Baku Yang Optimal Menggunakan Metode AHP Dan Fuzzy AHP: Studi Kasus Di PT. XYZ. Jurnal Teknik Industri ISSN: 1411-6340 234

[13] Pujawan, I N. 2010. Supply Chain Management. Surabaya: Guna Widya.

[14] Purwati, Dewi. 2014. Pengukuran Kinerja Rantai Pasok Menggunakan Model

[15] SCOR (Supply Chain Operation Reference) Di PT. Pacific Brands Indonesia. Jakarta: Universitas Al Azhar Indonesia.

[16] Saaty, Thomas L. 1994. Fundamentals
Of Decision Making and Priority Theory With The Analytic Hierarchy Process. Pittsburgh,USA.

[17] Said, Anya M. 2015. Pengukuran Kinerja Rantai Pasok pada PT. Louserindo Megah Permai Menggunakan Model SCOR (Supply Chain Operation Reference). Jakarta: Universitas Al Azhar Indonesia.

[18] Sigit Budi, Permana. 2013. Sistem Pendukung Keputusan Pemilihan Program Studi di UIN Sunan Kalijaga Menggunakan Metode Analytical Hierarchy Process (AHP). Skripsi Fakultas Sains DaTeknologi UIN Sunan Kalijaga Yogyakarta

[19] Sigalingging. 2011. Pendekatan FuzzyAnalytic Hierarchy Process Dalam Pemilihan Konsep Produk. http://repository.usu.ac.id/bitstream/12 3456789/25466/3/Chapter\%20II.pdf

[20] Simanjuntak, Payaman J. 2005. Manajemen dan Evaluasi Kinerja. Jakarta: FE UI.

[21] Simchi-Levi, David.,Kaminsky, Philip and Simchi-Levi, Edith. 2004. Managing The Supply Chain. New York: The McGraw-Hill.

[22] Sonata, Y. \& Azmi, M. 2010. Penerapan Metode AHP Dalam Menentukan Siswa Berprestasi. Skripsi Teknologi Informasi. Politeknik Negeri Padang.

[23] Sulistiana, Winda. Analisis Pemilihan Supplier Bahan Baku Dengan Menggunakan Metode Fuzzy Analytical Hierarchy Process (FAHP). Fakultas Teknologi Industri, Institut Teknologi Adhi Tama Surabaya.

[24] Supply Chain Council. http://www.supply-chain.org. 2010. Supply Chain Operations Reference Model SCOR version 10.0. Washington DC.

[25] Stevenson, William J. 2009. Operation Management 10th Edition. USA: McGraw-Hill.

[26] Turban, et al. 2004. Electronic Commerce: A Managerial Perspective. New Jersey: Prentice Hall.

[27] Wahyuni, Sri. Sistem Pendukung Keputusan Model Fuzzy AHP Dalam Pemilihan Kualitas Perdagangan Batu Mulia. Jurusan Ilmu Komputer dan Elektronika, FMIPA UGM, Yogyakarta 


\section{Lampiran}

Tabel 5. Rekapitulasi SCOR

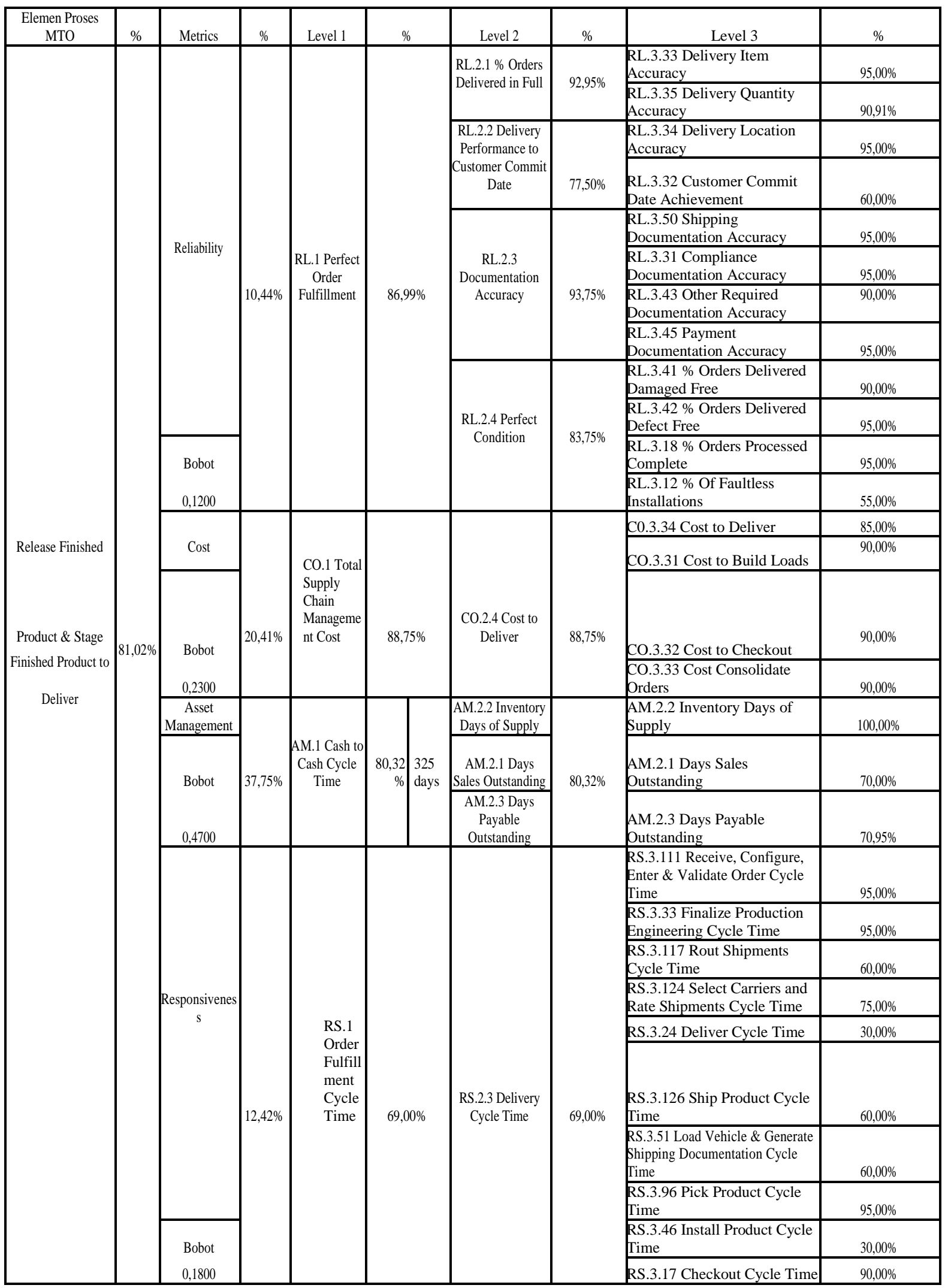

